TITLE:

\title{
Person-based organisation in working memory
}

$\operatorname{AUTHOR}(S)$ :

Ishiguro, Sho; Saito, Satoru

CITATION:

Ishiguro, Sho ...[et al]. Person-based organisation in working memory. Quarterly Journal of Experimental Psychology 2019, 72(6): 1439-1452

ISSUE DATE:

2019-06-01

URL:

http://hdl.handle.net/2433/245400

\section{RIGHT:}

This is the accepted manuscript of the following article: Sho Ishiguro, Satoru Saito. Person-based organisation in working memory. 'Quarterly Journal of Experimental Psychology' 72(6) 1439-1452. () Experimental Psychology Society 2018. DOI: 10.1177/1747021818794541.; この論文は出版社版でありません。引用の際には出版社版をご確認ご利用く ださい。; This is not the published version. Please cite only the published version. 
Running head: PERSON-BASED ORGANISATION IN WM

\title{
Quarterly Journal of Experimental Psychology
}

\author{
Person-Based Organisation in Working Memory \\ Sho Ishiguro ${ }^{\mathrm{a}, \mathrm{b}}$ and Satoru Saito ${ }^{\mathrm{a}}$

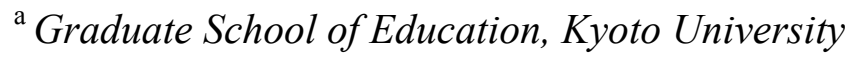 \\ ${ }^{\mathrm{b}}$ Japan Society for the Promotion of Science
}

Author Note

This work was supported by the Kyoto University Design School, a Grant-in-Aid for Scientific

Research [grant number 25285200] from the Ministry of Education, Culture, Sports, Science and Technology in Japan, and a Grant-in-Aid for Japan Society for the Promotion of Science (JSPS) fellows [grant number 17J05372].

Corresponding authors. Graduate School of Education, Kyoto University, Yoshida-honmachi, Sakyo-ku, Kyoto 606-8501, Japan (S. Ishiguro). E-mail address: ishiguro.sho.grocio@gmail.com (S. Ishiguro) saito.satoru.2z@kyoto-u.ac.jp (S. Saito).

Disclosure of Interest. The authors report no conflicts of interest.

Ishiguro, S., \& Saito, S. (2019). Person-based organisation in working memory. Quarterly Journal of Experimental Psychology, 72(6), 1439-1452. https://doi.org/10.1177/1747021818794541 


\begin{abstract}
Working memory (WM) helps maintain information during a variety of cognitive activities in scholastic and social situations. This study focused on a social aspect of WM, specifically, how it maintains information related to people. We investigated person-based organisation of information across four experiments using the reading span task (RST). Person information (i.e., an occupational title) was provided with sentences manipulated across conditions. In Experiment 1, consistent with the assumption that person-based organisation exists in WM, participants performed better when they could easily organise target items in a person-based manner (personbased organisation) than when they were prevented from using such information. Experiments 2 and 3 investigated the process of person-based organisation using alphabetical letters as targets (unlike words in Experiment 1), which prevented possible semantic associations between person information and target items. Experiment 2 replicated Experiment 1, suggesting that contextual retrieval is critical in person-based organisation. Experiment 3 showed the person-based organisation effect even after controlling for the difficulty of the process component in the RST. The results of Experiments 2 and 3 suggest that person information could serve as contextual retrieval cues in WM. Experiment 4, which did not show the organisation effect based on information about an object (i.e., a fruit name), suggests along with Experiments 1-3 that the observed organisation effect in Experiments 1-3 was specific to person information. In addition to showing the enhanced WM performance by person-based organisation, we have suggested contextual cue-dependent retrieval as the underlying cognitive process. [243 words]
\end{abstract}

Keywords: working memory, person memory, context, cue-dependent retrieval 


\section{Person-Based Organisation in Working Memory}

Working memory (WM) refers to a cognitive function for retaining information in one's mind while performing a variety of activities, or the cognitive system realising that function (Baddeley, 2000; Logie, 2011; Miyake \& Saito, 2001). In the current paper, we addressed the WM functioning of retaining social information in light of the view that WM plays in social activities (Meyer \& Lieberman, 2012; Meyer, Spunt, Berkman, Taylor \& Lieberman, 2012) by focusing the person-based organisation effect. At the onset, we will briefly describe WM in general and then, explain social WM and the possible person-based organisation effect of WM.

The measurement of WM requires capturing the dynamic aspect of the memory function, typically including the processing component as well as the storage component (Bayliss, Jarrold, Gunn \& Baddeley, 2003; Daneman \& Carpenter, 1980). Notably, these two components are not independent but interconnected. The processing component may impede the storage component because processing consumes limited resources that are shared with storage or it temporarily suspends storage (Barrouillet, Bernardin, Portrat, Vergauwe \& Camos, 2007; Barrouillet \& Camos, 2012; Daneman \& Carpenter, 1980; Portrat, Barrouillet \& Camos, 2008; Towse \& Hitch, 1995). Alternatively, processing facilitates storage in a certain situation (McCabe, 2008; Towse, Cowan, Hitch \& Horton, 2008). McCabe (2008) compared immediate and delayed recall for a WM task (complex span task) and a short-term memory task (simple span task). On immediate recall, more items learned during a short-term memory task were recalled than were items learned during a WM task. In contrast, in delayed recall, more items learned during a WM task were recalled than were items learned during a short-term memory task. McCabe suggested that the processing phases of the WM task allowed covert retrieval practice, which created retrieval cues that could be used in delayed recall. One of the most prominent features of the measures of 
WM is that individual differences in those measures explain variances in performance of complex activities better than those in short-term memory measures do (Conway, Kane, Bunting, Hambrick, Wilhelm \& Engle, 2005; Daneman \& Carpenter, 1980; Daneman \& Merikle, 1996; Engle, Tuholski, Laughlin \& Conway, 1999; but see also Unsworth \& Engle, 2007b), despite similarities in WM and short-term memory (Neath, VanWormer, Bireta \& Surprenant, 2014; Tehan, Hendry \& Kocinski, 2001). In fact, incorporating the processing component in a memory task (i.e., a WM task) leads to high correlations between WM performance and performance in a variety of complex cognitive tasks such as language comprehension tests (for a review, see Daneman \& Merikle, 1996), math performance tests (for a review, see Raghubar, Barnes \& Hecht, 2010), SAT (Turner \& Engle, 1989), and fluid intelligence tasks (Engle et al., 1999).

\section{WM and Social Settings}

Among the complex cognitive activities that we face in daily life is social interaction with other individuals, which has received relatively little attention in WM research compared to scholastic activities. Social interaction requires WM because it needs retaining information about a person while performing activities (social working memory; Meyer \& Lieberman, 2012; Meyer et al., 2012). For example, when we meet a male neighbour, we track information about him, such as what he had said and his facial expressions, while talking to and listening to him. We do not passively receive a stream of information but gather parts of information temporarily interrupted by the processing that we are engaged in (cf. time-based resource sharing account for WM; Barrouillet et al., 2007; Barrouillet \& Camos, 2012; Portrat et al., 2008). Additionally, we actively maintain them in the face of interference from processing (cf. interference-based forgetting account for WM; Oberauer, Farrell, Jarrold, Lewandowsky, 2016; Oberauer, 
Lewandowsky, Farrell, Jarrold \& Greaves, 2012; Saito \& Miyake, 2004). Therefore, WM functioning is assumed to support the retention of information about others.

Although a recent neuroimaging study (Meyer, Taylor \& Lieberman, 2015) reported on brain regions unique to social WM functioning (i.e., mentalising network) by contrasting the fMRI data during a social WM task and a cognitive WM task, it did not mean that performing a social task is independent of the cognitive WM network. In fact, their data also showed that the regions of the cognitive WM network are involved in both cognitive and social WM tasks, echoing the notion that engaging in a social activity recruits two networks: the cognitive WM network and the mentalising network (Meyer \& Lieberman, 2012; Meyer et al., 2012). Therefore, in the present study, it was assumed that the theories and findings of studies using cognitive WM tasks can be applied to social WM in part. This study aimed to extend the existing WM theories to social WM in which person information might have a strong impact.

\section{Person-based Organisation of Memory}

When we obtain information about a person, for example, by reading sentences, such as "John likes an apple" and "John lives in Tokyo", information seems to be organised in a personbased manner. The human associative memory theory (Anderson \& Hastie, 1974) proposed that a node of an individual, which can be accessed via name or occupation (e.g., "John" or "lawyer"), is linked with idea nodes (e.g., "likes an apple" and "lives in Tokyo") and that this connection between the individual node and idea nodes forms a person memory network. The presence of such person-based organisation of person information was also supported by an abundance of evidence from studies on impression formation (for a review, see Srull \& Wyer, 1989). In addition, person-based organisation is believed to be advantageous for the retrieval of information. A study on situation models showed that person-based organisation of information 
caused no fan effect, suggesting that it leads to an efficient retrieval of information (Radvansky, Spieler \& Zacks, 1993; but see also Bunting, Conway \& Heitz, 2004). With respect to comprehension, studies on situation models implied that readers comprehend the text along at least five dimensions: time, space, causality, intentionality, and most notably here, the protagonist (Zwaan, 1999; Zwaan, Langston \& Graesser, 1995; Zwaan \& Radvansky, 1998). According to this model, while reading the text, readers update their mental situation model corresponding to an event described in the text as a change occurs in any of these dimensions. During recall, information on a dimension, such as a protagonist, is thought to serve as a retrieval cue for the memory of the text (Taylor \& Tversky, 1997). A recent work also indicates the existence of the protagonist dimension in film comprehension (Zacks, Speer \& Reynolds, 2009). Thus, a broad range of literature implies that person-based organisation is a common and effective way of handling information. Given the commonality and effectiveness of person-based organisation, the person-based organisation of information may prevail even in WM.

\section{Overview of the Current Study}

The purpose of the present study was to test the presence of person-based organisation in WM and examine the underlying cognitive process of this organisation. In four experiments, we used the reading span task (RST) (Daneman \& Carpenter, 1980) as a WM measure because its validity and reliability have been established (Conway et al., 2005). First, as an exploratory experiment, we tested whether a manipulation that encourages person-based organisation enhances WM performance (Experiment 1). This would indicate the presence of person-based organisation in performing the WM task. One possible interpretation of the results is based on Unsworth et al.'s WM model (Unsworth \& Engle, 2007a; Unsworth, Fukuda, Awh, \& Vogel, 2014; Unsworth \& Spillers, 2010) that consists of attention-based maintenance and cue- 
dependent retrieval in WM (for cue-dependent retrieval in WM, see also Ericsson \& Kintsch, 1995). We supposed that the representation of a person can act as a retrieval cue (Taylor \& Tversky, 1997). Nevertheless, it was necessary to replicate the results and investigate what kind of retrieval cue the person representation serves as. In Experiment 2, we examined whether person representation can serve as a contextual retrieval cue rather than a retrieval cue based on semantic association. Target items were changed to alphabetical letters from words in order to prevent a semantic association between the target items and person information. Although we attempted to facilitate person-based organisation through the manipulations used in Experiments 1 and 2 , we tried to validate the account that person representation works as a retrieval cue through another experimental manipulation in Experiment 3; that is, decreasing the efficiency of retrieval cues based on the person representation by repeating the same person information throughout the experiment (i.e., through cue-overload; Watkins \& Watkins, 1975). It was expected that such a manipulation would worsen WM performance if person representation is used as a cue (Experiment 3). In Experiment 3, we also controlled for a possible confounding factor that existed in Experiments 1 and 2, the difficulty of processing. In Experiment 4, we also investigated whether the observed organisation effect was specific to person information using object information in the RST.

The speculation that WM has cue-dependent retrieval sub-process was supported by experiments setting sentences in RST (Schroeder, Copeland \& Bies-Hernandez, 2012; Towse et al., 2008; Towse, Hitch, Horton \& Harvey, 2010), phonological similarity (Chow, Macnamara \& Conway, 2016; Copeland \& Radvansky, 2001; Macnamara, Moore \& Conway, 2011), and semantic category (Liesefeld, Hoffmann \& Wentura, 2016) as cues. Based on Unsworth and Engle's WM model, we assumed that contextual information should work as a retrieval cue (e.g., 
Unsworth \& Engle, 2007a). Here, "context" refers to the environmental information in which items are learned (for a review, see Smith \& Vela, 2001). Note that "context" can act as a retrieval cue through temporal co-occurrence of an environment and items, although a semantic association of the environment with the items is not necessary here. For example, in a classic context-dependent memory study (Godden \& Baddeley, 1975), items were randomly selected, and thus, it was not that target items learned under the sea condition were thematically related to the sea. Although Schroeder et al. (2012) used term context as the context of the story in their WM study, story context includes semantic relations among the story and items. It differs slightly from the context assumed in Unsworth and Engle's (2007a) study and in contextdependent memory research.

Thus, the second purpose of Experiments 2 and 3 was to examine retrieval based on contextual cues in WM by an experimental approach, using person information in RST.

\section{Experiment 1}

The purpose of Experiment 1 was to test the presence of person-based organisation in WM.

\section{Method}

Participants. Thirty-two undergraduate and graduate students (10 females and 22 males), aged between 18 and 24 years, from Kyoto University, participated in the experiment. The sample size was determined based on the assumption that the effect size is medium (i.e., $d z=0.5$; see also Cohen, 1988) by referring to the comparable experiments (e.g., Schroeder et al., 2012). In order to secure the statistical power (i.e., $1-\beta$ probability $)=0.8$ with a one-tailed hypothesis $(\alpha=$ 0.05), a sample of $N=27$ is needed according to $\mathrm{G} *$ Power 3 software (Faul, Erdfelder, Lang, \& Buchner, 2007). We slightly increased the sample size to $N=32$ because counterbalancing the 
presentation order of conditions and materials was needed and we hoped to increase the power to detect the possible effect. The actual power was 0.87 with the effect size $=0.5$ and the sample size $=32$. Students whose first language was Japanese were recruited. They received a book coupon (1000 JPY) for their participation.

Materials. Three RSTs were used: a short form of a standard version of Japanese RST (Osaka, 2002) and two person RSTs. The original form of the standard Japanese RST comprises 20 trials. In this experiment, 12 of the 20 trials were conducted. The sentences of the Japanese RST were collected from textbooks in Japanese (for details see Osaka, 2002). Some sentences in the Japanese RST include person information, and their person information is strongly associated with the meaning of the sentence (e.g., "Farmers hoped for a rich harvest of rice and wheat"), whereas other sentences do not include person information (e.g., "Having the knowledge of English grammar does not assure good communication in English"). It makes it difficult to manipulate person information with the standard Japanese RST. Thus, in order to manipulate person information systematically, two person RSTs were developed for use in Experiment 1 according to the following steps: 1) selecting words, 2) creating sentences for each word, 3) allocating sentences to trials of RST, and 4) filling sentences with occupational titles (see supplemental material for target words and sentences used in tasks).

First, 42 separate semantic categories were selected from the studies of Akita (1980), Matsui and Nakatsubo (2007), and Ogawa (1972). Then, from each category, two words with high imageability and frequency were selected. Selecting words from separate categories reduced the probability of words having semantic associations with each other. Imageability and frequency of words were referred to in the NTT Japanese psycholinguistic database (Amano \& Kondo, 2000; Sakuma et al., 2005). The length of these words was restricted to 3 or 4 morae in a 
phonological form. Two words from each category were assigned to Word List A or Word List B, respectively, with the constraint that half of the words in Word List A were relatively more imageable than the remaining words in the same category, which were assigned to Word List B. This procedure prevented an imageability bias across lists. The obtained lists did not differ in the mean values of imageability, $t(82)=0.64, p=0.53$ (List A: 6.18, List B: 6.25 ) or the mean values of log-transformed frequency (base 10), $t(80)=0.20, p=0.84$ (List A: 3.02, List B: 3.05, the values of the frequency of two words were missing in the database).

Second, sentences were created for each word (e.g., "A person wiped a table and snacked on cookies" with the target being "cookies"). These sentences described common human behaviours, which everyone does or may do, but were designed not to convey the gender or stereotypical characteristics. Some sentences started with an adverbial phrase or clause, not with the subjective noun. This is because it was linguistically natural for some sentences and also to prevent possible readers' inattention by repeating the subjective noun at the same position. The number of Japanese characters in the sentences varied from 20 to 27.

Third, 42 sentences in each list were assigned to three sets each, for trials comprising two, three, four, and five sentences (12 sets for each list). Sentences were selected so that the semantic association of sentences within a set was minimised. Each set was designed to be used in each trial of the RST.

Fourth, "a person" part of each sentence was substituted with an occupational title from Akita (1980) in a manner corresponding to the two conditions in the experiment. Using the Match software (van Casteren \& Davis, 2007), two matched lists of 12 occupational titles in terms of the word length in mora and log-transformed frequency (base 10) were created. For most of the occupational titles used, the values of imageability were not available and not 
counted. These two occupation lists were named Occupation List 1 and Occupation List 2. There were no statistical differences in the mean length of occupational titles between the two lists (List 1: 4.1 morae, List 2: 4.3 morae), $t(22)=0.53, p=0.60$. For log-transformed frequency (base 10), there were no differences between the two lists (List 1: 3.36, List 2: 3.26), $t(22)=0.35$, $p=0.73$. Experiment 1 had two conditions: single person condition and multiple person condition. A combination of word lists, occupation lists, and conditions was created using a Latin square design. For example, if the combination of Word List A and Occupation List 1 was used for the single person condition, the combination of Word List B and Occupation List 2 was used for the multiple person condition.

For the single person condition, the occupational title was the same for sentences within a trial (Figure 1). As the trial changed, the occupational title also changed. Twelve occupational titles were randomly assigned to the 12 trials. For the multiple person condition, several randomly-selected occupation titles were used in sentences within a trial (Figure 1). As the sentence changed, the occupational title also changed. Twelve occupational titles were repeatedly used across trials but a title was not repeated within a trial.

[Figure 1 near here]

The first sentence in the single person condition and all sentences in the multiple person condition did not have a demonstrative for occupational titles ("sono" meaning "the" in Japanese). The occupational titles in the second or later sentences in the single person condition had a demonstrative (e.g., "sono sensei", which is "the teacher" for Japanese). The presentation order of the sets and sentences within each set for these RSTs were randomised for each participant. Given the characteristic of the Japanese language, target words were not the final words in a sentence, and they were underlined with a red line. 
Procedure. For all three RSTs, participants were told that they need to read the sentences on the computer screen aloud while retaining targets and recall them orally (Figure 2). The procedure was based on a previous study (e.g., Tanaka, Sugimoto, Tanida \& Saito, 2014). After two practice trials, they completed the standard Japanese RST first and then the two conditions of person RSTs (the order of the two conditions were counterbalanced). Each trial started with a fixation ("+"), which was followed by the presentation of several sentences with red underlines one-by-one, after which a recall probe (“?”) was displayed with a brief beep sound. Each time the participants finished reading a sentence, the experimenter pressed a key to show the next sentence or the recall probe. The lapses from each stimulus' onset to the experimenter's each key press were measured by a computer as the reading time for a sentence (see Appendix for the analysis of reading time). The position of the start point of the sentences and the fixation was vertically centred and horizontally set leftwards. This assured that the sentences appeared at the same position as the fixation, regardless of the length of the sentence. Participants were told that the lists comprised two to five items. They, however, did not know how many sentences were going to be shown in a given trial. This procedure prevented them from using strategies based on the number of upcoming items (Engle, Cantor \& Carullo, 1992). During recall, they first recalled the targets in the correct position. When they could not remember a target's position, they were asked to say "pass" (e.g., when they could not remember the target of the second sentence, they would say, "cookie, pass, piano"). After reporting this serial recall, they were encouraged to recall targets in any order if they remembered targets but not their positions.

To discourage guessing, participants were asked to recall only the targets that they remembered. When they finished recalling the items, they said, "I am finished". Then, when they were ready, they said "I am ready" to let the experimenter start the next trial. ${ }^{1}$ Participants took 
breaks of at least three minutes between each RST and completed three RSTs. All the participants, however, were allowed to interrupt between trials and take rest at any time they wished.

[Figure 2 near here]

\section{Results and Discussion}

Since we were uncertain whether possible person-based organisation affects order memory and/or item memory, we used two scoring methods of correct-in-position and item correct. Correct-in-position scores, which have been commonly adopted in a complex span task (e.g., Unsworth et al., 2014), reflect both item and order memory, whereas item correct scores are sensitive to item memory. In either method, the sum of the recalled items was used, and the possible range of scores was 0-42 (see also Friedman \& Miyake, 2005). Frist, we counted the total number of correctly recalled items at their correct position across all trials (correct-inposition). Second, we counted the total number of correctly recalled items at any position was used (item correct). That said, analysing the results of item correct scoring provided the similar results of correct-in-position, and we report only the results of correct-in-position scoring.

The scores on the standard Japanese RST were regarded as the criterion, and the correlations between the scores and the other two scores were checked (Table 1). The correlation coefficient of two different tasks was affected by their measurement errors, leading to the attenuation of correlation coefficients (see also Conway et al., 2005), and a previous study showed that the correlation coefficients from different RSTs could be modest, ranging from .52 to .63 (Waters, 1996). Considering the statistical limitations and the previously reported correlation coefficients, the person RST was judged to serve as a measure of WM.

[Table 1 near here] 
The main purpose of this experiment was to test whether the contextual information provided by person information can affect WM performance. As the direction of the possible person-based organisation effect was expected, one-tailed paired t-test was used here and in the subsequent tests on RSTs. The mean score in the single person condition was higher than that in the multiple person condition, $t(31)=2.54, p=.008, d z=0.45$ (Table 1). The mean difference in the WM scores in the two conditions was $2.81(95 \% \mathrm{CI}=0.56,5.07)$.

The results showed that WM performance increased in the single person condition, suggesting that person-based organisation works on WM. Importantly, because occupational titles were presented in both the conditions, providing person information per se was not the determinant of the increase in WM performance in Experiment 1 but the way of providing person information was; providing one person's information within a trial had a positive effect on WM performance.

To confirm the person-based organisation in WM, a replication is required. More importantly, the cognitive process underlying this effect needs to be identified. Within the framework of a WM model (Unsworth \& Engle, 2007a), person-based organisation could be interpreted in terms of cue-dependent retrieval sub-process in WM, by supposing that person representation serves as a cue (Taylor \& Tversky, 1997). Specifically, participants could relate targets items to a person and retrieve items by using the representation of that person as a cue. Even if this is the case, however, the nature of person representation as a cue is unclear. It may serve as a semantic cue and/or a contextual cue for items. To examine this point, in the next experiment, we examined the effect of person information provided as contextual information. 


\section{Experiment 2}

The purpose of Experiment 2 was to test whether the representation of people, provided as contextual information, can enhance WM performance, and to replicate the results of Experiment 1.

If a semantic association between the person information and items is a necessary factor, the person-based organisation effect should not be observed when the association is minimised. Alternatively, if a semantic association is an additional or optional factor, simply giving person information as contextual information should be sufficient for the presence of the effect.

To examine the contextual effect of person representation, targets were changed to alphabetical letters, such that it would be difficult for participants to associate letters with a given person semantically (e.g., Relating "Q" and "L" to a "Police officer" seems difficult). It is worth noting that the sentences and occupational titles were given in Japanese characters, and targets were alphabetical letters so that the semantic association would be very difficult. We presented the letters following each sentence. Participants read each sentence and retained each letter.

\section{Method}

Participants. Thirty-two undergraduate and graduate students (14 females and 18 males), aged between 18 and 25 years, from Kyoto University, participated in the experiment. In power planning, we determined the sample size as $N=32$ based on the results of Experiment 1 (the effect size, $d z=0.45$ ) and statistical power $=0.8$. All participants were native Japanese speakers and had not taken part in Experiment 1. The participants (i.e., university students in Japan) had the experience of learning English and could properly pronounce the alphabetical letters. This is also true for the participants in the subsequent experiments. Participants received 1000 JPY for their participation. 
Materials. For the three RSTs including the standard Japanese RST, the sentences in Experiment 1 were used but targets were changed to alphabetical letters. The following nine phonologically distinct target letters were used: B, F, H, J, L, M, Q, R, and X in order to prevent phonological similarity from affecting the performance (based on Kane et al., 2004). These nine letters were allocated as targets for 42 sentences for each test under the constraints that the occurrence frequency of the nine letters was almost the same (4 or 5 times), the same letters never occurred in a trial, and the letters in a trial did not compose an acronym. Each sentence was followed by a target letter with a space between the sentence and the target (Figure 3). As words were not the targets, the red underlines used for the target words in Experiment 1 were removed.

Procedure. The procedure was identical to that in Experiment 1, except that the material was modified, and participants were only required to serial recall. Participants were asked to read out loud the sentence and letter presented on the computer screen. At recall, participants serially recalled the target letters that they remembered. As in Experiment 1, they were asked to say "pass" when they could not recall the correct target at its position.

[Figure 3 near here]

\section{Results and Discussion}

As participants were only asked serial recall, only correct-in-position scoring was used. Item-correct scoring was omitted in Experiment 2 for two reasons. First, item-correct scoring was judged redundant as the results of Experiment 1 showed similarities in the results by correctin-position and item-correct scorings. Second, because the nine letters were used repeatedly, item correct scoring could not be a sensitive measure.

The data for Experiment 2 are presented in Table 1. Although the standard Japanese RST was modified (targets were changed) and so it could not serve as a conventional criterion, the 
correlations of the three RSTs are also shown. The mean score for the single person condition was higher than that for the multiple person condition, $t(31)=2.10, p=.022, d z=0.37$. The mean of the differences was $1.81(95 \% \mathrm{CI}=0.05,3.58)$.

Under the condition of preventing semantic associations, presenting person information in each trial enhanced WM performance. These results suggest that person representation works as contextual cues, and the semantic association between person information and target items is not a necessary factor for person-based organisation in WM.

Although Experiment 2 perfectly replicated the results of Experiment 1, in order to validate the account that person representation serves as a retrieval cue, it is desirable to examine the person-based organisation effect by another experimental manipulation. Furthermore, Experiments 1 and 2 did not control for the difficulty in processing the RST. Reading multiple occupational titles in a trial seems more difficult than reading only one title in a trial, which may have led to the differences in the scores between the two conditions in Experiments 1 and 2 (i.e., a possible confounding factor). In fact, manipulating the difficulty of the processing component can affect WM performance (Barrouillet et al., 2007). This factor was addressed in the following experiment.

\section{Experiment 3}

Experiment 3 was performed to explore person-based organisation effect by another experimental manipulation that targets cue-dependent retrieval and to control a possible confounding factor, the difficulty of the processing components.

One prediction from the cue-dependent retrieval hypothesis is that experimentally decreasing the effectiveness of cues worsens WM performance. In Experiment 3, the constant person condition was introduced as a condition to lessen the effectiveness of cues by repeating 
the same person information across trials (i.e., cue-overload; Watkins \& Watkins, 1975). The cue-overload effect is, in fact, addressed in Unsworth and Engles' WM model (2007a). According to this model, the role of a contextual cue is to delimit a search set, which includes target items and extraneous items. A cue associated with many items in the previous trials lets these items as extraneous items into a search set, making the probability of recalling target items in the current trial small. Thus, the effectiveness of a cue depends on how specifically it delimits a search set. Given the contextual association between person information and items, repeating the same person information should make a contextual cue provided by person information ineffective because such a contextual cue could be associated with items in the previous trials and cannot be uniquely associated with the target items in the current trial.

The difficulty in processing was controlled for in order to address the alternative explanation that the differences in difficulty of processing components in the two conditions caused the differences in WM performance. Since occupational titles varied within a trial in the multiple person condition, reading the sentences may have been more difficult than reading the sentences in the single person condition, in which only one occupational title was used within a given trial. The appearance of multiple people may also increase the amount of interfering information, which lessens WM performance according to the interference-based account (Oberauer et al., 2012). In Experiment 3, the difficulty of processing in the constant person condition was designed to be equivalent to or lower than that used in the single person condition, which excludes this possible confounding factor.

In Experiment 3, the single person condition, which was the same as that in Experiment 2, was compared with the constant person condition (Figure 1), in which one occupational title was used repeatedly across trials. For the constant person condition, only the first sentence appeared 
without the Japanese demonstrative, and the remaining sentences (41 sentences) had the demonstrative. This procedure also equated the differences in difficulty arising from the length of sentences because both the second or later sentences in the trials in the single condition and all except the first sentence in the first trial in the constant person condition had the demonstrative. For the first sentence in all trials after the first trial, the length of sentences differed between the two conditions. The length of first sentences, however, was thought to have little influence on RST performance since participants did not start encoding any target items before reading the first sentence in each trial.

\section{Method}

Participants. Because in Experiments 2 and 3 the target type was the same (letters), based on the effect size of Experiment $2(d z=0.37)$, a power analysis was performed. The power analysis showed that at least 47 participants were required to secure a statistical power ( 1 - $\beta$ probability) $=0.8$ for a one-tailed test when the effect size was $d z=0.37$. For balancing factors, such as presentation order of conditions and materials, the sample size was 48 .

Forty-eight undergraduate and graduate students (14 females and 34 males), aged between 18 and 31 years, from Kyoto University, participated in the experiment. Students whose first language was Japanese and who had not taken part in Experiments 1 or 2 were recruited. They received 1000 JPY for their participation. 
Materials and procedure. The procedure was the same as that in Experiment 2, except that the multiple person condition was substituted with the constant person condition. For the constant person condition, one occupation title was repeatedly used across all trials (Figure 1). This occupational title was randomly selected from the list of 12 titles that were not used for the single person condition.

\section{Results and Discussion}

One participant was excluded from analysis due to being distracted during the tasks. The participant responded with "pass" or omitted the responses for half of the items in the RST (21 items out of 42 items) including easy trials of 2 items, which indicated his distraction. The data for Experiment 3 are presented in Table 1. The mean score in the single person condition was higher than that in the constant person condition, $t(46)=2.07, p=.022, d z=0.30$. The mean of the differences was $1.13(95 \% \mathrm{CI}=0.03,2.22)$.

Experiment 3 showed that presenting different occupational titles in each trial had a positive effect on WM performance compared to presenting the same occupational title across all trials. The results are consistent with the prediction based on the contextual cue effect that the manipulation targeting the effectiveness of the cues provided by person information affects WM performance even after controlling for the task difficulty. The fact that the results of the three experiments converged indicates that person representation affects WM as a contextual cue.

Experiments 1-3 directly targeted person information but it is not clear whether the observed organisation effect is specific to person information. To examine this, Experiment 4 was performed.

\section{Experiment 4}


Experiment 4 was performed to test whether the observed organisation effect in Experiments 1-3 can be seen in RST with the subjective or objective noun of sentences being the names of objects (i.e., fruits). In Experiment 4, the two ways of presenting information in Experiment 3 were adopted: changing the types of information across trials and repeating the same kind of information across trials. The single person condition was replaced with the single object condition and the constant person condition with the constant object condition. If the observation in the previous experiment is not specific to person information, the scores in the single object condition should be higher than that in the constant object condition.

\section{Method}

Participants. A power analysis was conducted based on the effect size of Experiment $3(d z=$ 0.30) because, in the current experiment, the target items were alphabetical letters, and the contextual information was presented similar to that in Experiment 3. At least 71 participants were required to secure a statistical power $(1-\beta$ probability $)=0.8$ for a one-tailed test supposing the effect size $(d z)=0.30$. For balancing of factors, the sample size was set as 72 .

Seventy-two undergraduate and graduate students (25 females and 47 males), aged between 18 and 35 years, from Kyoto University, participated in the experiment. Students whose first language was Japanese were recruited. None of the participants took part in the previous experiments. They received 1000 JPY for their participation.

Materials and procedure. The procedure was similar to that of Experiment 3, except that the sentences for RSTs were changed. In Experiment 4, new object RSTs were created according to the following steps (see also supplemental materials). First, 24 fruit names were selected from the fruit category in Akita's (1980) study, to create two lists of fruits. The names of these fruits 
were divided into Fruit List 1 or Fruit List 2 such that these lists were equivalent in terms of mora and frequency by using the Match software (van Casteren \& Davis, 2007).

For these lists, there were no statistical difference in the mean values of mora length, $t(22)=0.71$, $p=0.48,($ Fruit List 1: 3.67, Fruit List 2: 3.25) or the mean values of log transformed frequency (base 10), $t(22)=0.39, p=0.70$, (Fruit List 1: 2.32, Fruit List 2: 2.43). Second, two sentence lists of 42 generic descriptions of a fruit were created (e.g., "Because a fruit was organic, it was infested with insects"). These lists were named List A and List B. The length of these sentences ranged from 20 to 27 , and the mean values of the length of sentences in these lists did not differ from those used in Experiments $1-3, F(3,164)=0.97, p=0.41$. As in Experiments $1-3$, the sentences in each list were assigned to three sets each, for trials comprising two, three, four, and five sentences. "A fruit" part of each sentence was replaced with a fruit name from Fruit List 1 or Fruit List 2. In the single object condition, the name of a fruit changed as the trial changed. In the constant object condition, the same name of a fruit was repeated across all trials. The name of a fruit in the constant object condition was randomly selected from the list that was not used in the single object condition. As in Experiment 3, only the first sentence in each trial in the single object condition and the first sentence in the first trial in the constant object condition did not have the demonstrative. Sentence lists, fruit lists, conditions, and the order of conditions were counterbalanced by participants.

\section{Results and Discussion}

The data of two participants for the standard Japanese RST were lost due to equipment malfunction and excluded in the statistical analysis of the standard Japanese RST, while the data of all participants for the two object RSTs were available and included in the statistical test (Table 1). The direction of the difference in the scores between the two conditions suggests that 
the mean score in the single object condition was lower than that in the constant object condition: the mean of the differences was $-0.42(95 \% \mathrm{CI}=-1.40,0.57)$. These results are different from the results of Exp. 1 - 3 and also suggest a possible null effect. As to investigate the null effect, the Bayes factor was calculated by using Bayesian paired samples t-test of JASP software (Wagenmakers et al., 2018). The Bayes factor in favour of the null hypothesis was $\mathrm{BF}_{01}=13.39$ with the null hypothesis: the mean scores of two conditions are the same, and the alternative hypothesis: the mean score of the single object condition is greater than that of the constant object condition. This can be considered as strong evidence for a null effect according to Jeffreys (1961, p. 432; see also Wagenmakers, Wetzels, Borsboom, \& van der Maas, 2011), which suggests that the scores in the two conditions did not differ from each other ${ }^{2}$.

Experiment 4 showed that the organisation effect was not observed in RST by varying the names of fruits. Note that we had adequate statistical power to detect a difference in the conditions. Moreover, the Bayes factor favoured the null effect. The results of Experiment 4 imply the person-specificity of the organisation effect in RST. This person-specificity is discussed in two different ways. One account assumes a certain mechanism unique to social information whereas the other assumes the general mechanism across social and non-social information. The latter supposes that the differences of the results of Experiment 3 and 4 arose from the quantitative differences of the saliency of social and non-social information, which theoretically admits an organisation effect based on object information (see General discussion).

\section{General discussion}

Experiments 1-3 demonstrated that participants' WM performance was enhanced when person-based organisation was facilitated. The findings also suggest that this person-based organisation effect relies on the contextual cue retrieval sub-process in WM (Experiments 2 and 
3). Experiment 4 suggests that this observed organisation is a person-specific effect because the object names did not lead to an organisation effect.

Experiment 1 showed that when presenting one person's information (i.e., one's occupational title) per trial, which was assumed to enable person-based organisation, participants recalled more target words as compared to when person-based organisation was unlikely to occur. This suggests that person-based organisation of information was used for WM. In Experiments 2 and 3, we investigated the cognitive process underlying the person-based organisation effect. We supposed that the retrieval process with contextual cues may implement person-based organisation as person representation serves as retrieval cues. In Experiment 2, the manipulation of presenting person occupation was identical to that in Experiment 1 but the target items were changed to letters, which prevented a semantic association between targets and person information. The scores in the condition facilitating person-based organisation were higher than those in the condition preventing person-based organisation. Assuming that person information serves as a contextual cue, we predicted that repeating the same person information across trials would decrease WM performance by decreasing the effectiveness of the person-related contextual cue. The results of Experiment 3 supported this assumption and showed that repeatedly presenting an occupational title decreases the scores compared to providing particular occupational titles in each trial. A possible confounding factor, difficulty in reading, was also controlled for in Experiment 3. Even though Experiments 2 and 3 differed in their procedures, the findings of these experiments indicate that person representation served as contextual cues. To clarify whether the organisation effect observed in Experiments 1-3 was person-specific, the subjective noun was replaced with an object name (i.e., fruit name) in Experiment 4. The results of Experiment 4 did not show an organisation effect, which suggests that an organisation effect 
observed in RST with the subjective noun or objective noun is person-specific. This personspecific effect or person-based organisation effect could be interpreted in two different ways.

First, it can be regarded to reflect a mechanism unique to social information, as indicated by a neuroimaging study (Meyer, Taylor \& Lieberman, 2015). Meyer and Lieberman (2012) proposed that mentalising network, which is functionally and anatomically distinct from cognitive WM network, supports WM for social information. An effect specific to social WM, such as the person-based organisation effect, might be a by-product of the functioning of the mentalising network. Nevertheless, the person-based organisation effect in the present study was not the effect of presenting social information per se, and social information was available even in both multiple person condition and the constant person condition. In this sense, our experiments differed from those of the previous studies on social WM, which mainly compared the effects of presenting social vs. non-social information. Further detailed research on the characteristics of social WM functioning is required.

Second, person-specificity can be interpreted to show the effectiveness of person information as retrieval cues within the framework of general memory theories. Studies that support the concept of social WM also show that the cognitive WM network is activated even in a social WM task (Meyer et al., 2012; Meyer et al., 2015), suggesting a shared neural mechanism responsible for both cognitive and social information (Meyer \& Lieberman, 2012). More importantly, the data from Experiments 1-3 of the present study follow the general memory principles such as the effects of contextual retrieval cues and cue-overload. Therefore, it is possible that a given mechanism at the neural level and/or the cognitive process level was responsible for both person information and object information in the current experiments. The differences between Experiments 3 and 4 can be attributed to the differences of the effectiveness 
or the availability of person information vs. object information; person information may be salient and readily used as retrieval cues (see also Rich \& Taylor, 2000).

In Experiment 3, we introduced the constant person condition such that difficulty in reading sentences of the constant person condition should be equivalent to or lower than that of the single person condition. Even if the single person condition had a disadvantage arising from this difficulty relative to the constant person condition, person-based organisation effect may have surpassed its disadvantage because of the effectiveness of person information. The null effect in Experiment 4 might not deny the existence of an organisation effect based on object information. Instead, it was possible that the weakly positive organisation effect was counteracted by the relative disadvantage of the single object condition arising from difficulty in reading, leading to its WM scores equivalent to that of the constant object condition. Following this reasoning, the results of Experiments 3 and 4 can be situated within the framework of general memory theories.

In fact, we observed that explaining the person-based organisation within the framework of general memory theories showed consistency with the previous studies and gave us important insights. This is discussed below based on these memory theories.

\section{Contextual Effects on WM}

Although the effect sizes were not large in Experiments $1-3$ ( $d z$ s ranging from 0.30 to 0.46), the demonstration of the contextual cue effect on the memory for person information has theoretical implications.

Experiments 2 and 3 indicated that person representation works as contextual cues. This observed contextual effect driven by person representation can be interpreted as one instance of the contextual effect on WM in general. The significant roles of contextual information in 
memory retrieval have been established in a long history of memory research (see Greene, 1992). Unsworth and Engle's WM theory (Unsworth \& Engle, 2007a) was, in fact, based on previous memory studies on context (e.g., Glenberg \& Swanson, 1986; Raaijmakers \& Shiffrin, 1980). Some modern theories and models of human memory also have been developed by incorporating context as an integral part (e.g., Brown, Neath \& Chater, 2007; Davelaar, Goshen-Gottstein, Ashkenazi, Haarmann \& Usher, 2005; Farrell, 2012; Polyn, Norman \& Kahana, 2009a, 2009b). Polyn and colleagues' model for long-term memory or context maintenance and retrieval (CMR) model (Polyn et al., 2009a, 2009b) is related to the current study. According to the CMR model, information of tasks performed concurrently at study phases was encoded as source context and used as a retrieval cue for items at recall. Polyn et al. (2009b) showed that changes in the concurrent tasks led to organisation effects based on the type of the concurrent task in addition to temporal clustering. Supposing reading sentences in RST is a concurrent task, we infer that information in the sentences (e.g., occupational titles) can lead to organisation effects. While the CRM model primarily focuses on long-term memory (see Poyln et al., 2009b), some other models address short-term memory (or working memory) and long-term memory within their unified framework. For example, Farrell (2012) proposed a new framework of short-term memory and episodic memory in which segmented episodic clusters consist of one type of context (group context) that operates at the time of retrieval. It is assumed that if the group context is updated to another, events in the episodic cluster of the initial context become less accessible. In this case, the group context must be reinstated at the time of retrieval, and a failure to reinstate the context leads to the failure of retrieval of events within the context. In relation to the current study, Farrell (2012) indicated that in complex span tasks, a processing component is associated with a temporal context of an immediately preceding item in the span list, and the 
presentation of the next item to be memorised possibly updates the previous item context (e.g., Oberauer et al., 2012). Perhaps, person information in the single person condition in the present study might have united such continuously updated item contexts in a span list or provided an efficient list context containing the item contexts as the hierarchical context proposed by Farrell (2012). The higher level list context might have been immediately available at the time of recall and supported retrieval of items from the given list, leading to a better recall performance in the single person condition. Such higher level list contexts might have been unavailable or, at least, less efficient in the multiple person condition, and they could not provide useful contextual cues due to cue-overload in the constant person condition in the present study. This interpretation can explain the key difference between the single person condition and the constant person condition in Experiment 3, and it suggested the advantage of the unique context in terms of the usefulness of contextual cues.

Based on the above considerations, we can state that the most important theoretical contribution of this study is that it demonstrated an extension of a general memory framework (e.g., Farrell, 2012) to a social factor (i.e., person information). That is, it elucidates the cognitive mechanisms in the influence of social factors in WM.

\section{Person-Based Organisation in WM}

Person-based organisation has been well documented in studies on person memory and language comprehension (Anderson \& Hastie, 1974; Radvansky et al., 1993; Rich \& Taylor, 2000; Srull \& Wyer, 1989; Taylor \& Tversky, 1997). The findings of the present study are consistent with those of previous research and especially support studies on situation models. In language comprehension, a situation model is a mental representation of the description that is held in WM by definition (Zwaan \& Radvansky, 1998). According to these studies, 
comprehenders construct and update their situation model along at least five dimensions when reading (Zwaan et al., 1995). Thus, a change in a dimension is an important signal for updating the current situation model. A protagonist is assumed to be one of the five dimensions. Importantly, a change in the protagonist dimension more reliably influences text comprehension compared to the dimensions of time and space (Rich \& Taylor, 2000; Taylor \& Tversky, 1997). Thus, the protagonist dimension is critical in a situation model. Our current study can be interpreted within the framework of situation models. The manipulation of presenting the persons in Experiments 1 and 2 may correspond to the change in the protagonist in terms of situation models. Specifically, presenting several people in a trial (the multiple person condition) would have required frequent updating of the protagonist dimension. The updating within the same trial would have lessened the accessibility of the items presented prior to updating (for temporal change, Speer \& Zacks, 2005; for discussions, see Farrell, 2012 and the section of Contextual effects on WM). In contrast, presenting a person in each trial (the single person condition) did not require updating a situation model within a trial as in the protagonist dimension. It would not have led to a decrease in the accessibility of earlier items within a trial as mentioned above. At the same time, the change of protagonists corresponding to the change of trials may reduce the accessibility of the items in previous trials, preventing interference from the previous items. It may account for the higher scores in the single person condition compared to that in the constant person condition in Experiment 3. The single person condition involves change in the protagonists at a time appropriate for task performance. The differences between the conditions in the timing of situation model updating may have led to the differences in scores. As probably noticed, situation model updating is conceptually similar to updating of a higher level group context mentioned before (Farrell, 2012). Given that person information, and not 
object information, led to the detectable organisation effect on WM performance, a key difference between the explanations for Farrell's model and the situation model account is that the situation model account gives a special status to person information (i.e., the protagonist dimension). Further research that examines whether and how contextual updating in WM theories and the situation model updating relate to each other can facilitate our understanding of person-based organisation in WM.

[8425 words] 


\section{References}

Akita, K. (1980). Goju kategori ni zokusuru go no shutsugenhindo [The table of appearancefrequencies for verbal items in 50 categories]. Doshisha University Studies in Humanities (135), 42-87.

Amano, S., \& Kondo, T. (2000). NTT nihongo detabesu shirizu: Nihongo no goitokusei, tangohindo [Japanese NTT database series: Lexical properties of Japanese, Frequency]. Tokyo: Sanseido.

Anderson, J., \& Hastie, R. (1974). Individuation and reference in memory: Proper names and definite descriptions. Cognitive Psychology, 6(4), 495-514. doi:10.1016/00100285(74)90023-1

Baddeley, A. (2000). The episodic buffer: A new component of working memory? Trends in Cognitive Science, 4(11), 417-423. doi:10.1016/S1364-6613(00)01538-2

Barrouillet, P., Bernardin, S., Portrat, S., Vergauwe, E., \& Camos, V. (2007). Time and cognitive load in working memory. Journal of Experimental Psychology: Learning, Memory, and Cognition, 33(3), 570-585. doi:10.1037/0278-7393.33.3.570

Barrouillet, P., \& Camos, V. (2012). As time goes by: Temporal constraints in working memory. Current Directions in Psychological Science, 21(6), 413-419. doi:10.1177/0963721412459513

Bayliss, D. M., Jarrold, C., Gunn, D. M., \& Baddeley, A. D. (2003). The complexities of complex span: Explaining individual differences in working memory in children and adults. Journal of Experimental Psychology: General, 132(1), 71-92. doi:10.1037/00963445.132 .1 .71 
Brown, G. D. A., Neath, I., \& Chater, N. (2007). A temporal ratio model of memory. Psychological Review, 114, 539-576. doi:10.1037/0033-295X.114.3.539

Bunting, M. F., Conway, A. R., \& Heitz, R. P. (2004). Individual differences in the fan effect and working memory capacity. Journal of Memory and Language, 51(4), 604-622. doi: 10.1016/j.jml.2004.07.007

Chow, M., Macnamara, B. N., \& Conway, A. R. (2016). Phonological similarity in working memory span tasks. Memory \& Cognition, 44(6), 937-949. doi:10.3758/s13421-0160609-8

Cohen, J. (1988). Statistical power analysis for the behavioral sciences (2nd ed.). Erlbaum, Hillsdale, NJ.

Conway, A. R., Kane, M. J., Bunting, M. F., Hambrick, D. Z., Wilhelm, O., \& Engle, R. W. (2005). Working memory span tasks: A methodological review and user's guide. Psychonomic Bulletin \& Review, 12(5), 769-786. doi:10.3758/BF03196772

Copeland, D. E., \& Radvansky, G. A. (2001). Phonological similarity in working memory. Memory \& Cognition, 29(5), 774-776. doi:10.3758/BF03200480

Daneman, M., \& Carpenter, P. A. (1980). Individual differences in working memory and reading. Journal of Verbal Learning and Verbal Behavior, 19(4), 450-466. doi:10.1016/S0022$5371(80) 90312-6$

Daneman, M., \& Merikle, P. M. (1996). Working memory and language comprehension: A meta-analysis. Psychonomic Bulletin \& Review, 3(4), 422-433. doi:10.3758/BF03214546

Davelaar, E. J., Goshen-Gottstein, Y., Ashkenazi, A., Haarmann, H. J., \& Usher, M. (2005). The demise of short-term memory revisited: Empirical and computational investigations of recency effects. Psychological Review, 112(1), 3-42. doi:10.1037/0033-295X.112.1.3 
Engle, R. W., Cantor, J., \& Carullo, J. J. (1992). Individual differences in working memory and comprehension: A test of four hypotheses. Journal of Experimental Psychology: Learning, Memory, and Cognition, 18(5), 972-992. doi:10.1037/0278-7393.18.5.972

Engle, R. W., Tuholski, S. W., Laughlin, J. E., \& Conway, A. R. (1999). Working memory, short-term memory, and general fluid intelligence: a latent-variable approach. Journal of Experimental Psychology: General, 128(3), 309-331. doi:10.1037/0096-3445.128.3.309

Ericsson, K. A., \& Kintsch, W. (1995). Long-term working memory. Psychological Review, 102(2), 211-245. doi:10.1037//0033-295X.102.2.211

Farrell, S. (2012). Temporal clustering and sequencing in short-term memory and episodic memory. Psychological Review, 119(2), 223-71. doi:10.1037/a0027371

Faul, F., Erdfelder, E., Lang, A. G., \& Buchner, A. (2007). G* Power 3: A flexible statistical power analysis program for the social, behavioral, and biomedical sciences. Behavior research methods, 39(2), 175-191. doi:10.3758/BF03193146

Friedman, N. P., \& Miyake, A. (2005). Comparison of four scoring methods for the reading span test. Behavior Research Methods, 37(4), 581-590. doi:10.3758/BF03192728

Glenberg, A. M., \& Swanson, N. G. (1986). A temporal distinctiveness theory of recency and modality effects. Journal of Experimental Psychology: Learning, Memory, and Cognition, 12(1), 3. doi:10.1037/0278-7393.12.1.3

Greene, R. L. (1992). Human memory: Paradigms and paradoxes. Hillsdale, NJ: Erlbaum.

Godden, D. R., \& Baddeley, A. D. (1975). Context-dependent memory in two natural environments: On land and underwater. British Journal of Psychology, 66(3), 325-331. doi:10.1111/j.2044-8295.1975.tb01468.x

Jeffreys, H. (1961). Theory of probability (3rd ed.). Oxford, UK: Oxford University Press. 
Kane, M. J., Hambrick, D. Z., Tuholski, S. W., Wilhelm, O., Payne, T. W., \& Engle, R. W. (2004). The generality of working memory capacity: a latent-variable approach to verbal and visuospatial memory span and reasoning. Journal of Experimental Psychology: General, 133(2), 189-217. doi:10.1037/0096-3445.133.2.189

Liesefeld, H. R., Hoffmann, E., \& Wentura, D. (2016). Intelligence as the efficiency of cuedriven retrieval from secondary memory. Memory, 24(3), 285-294. doi:10.1080/09658211.2014.1002412

Logie, R. H. (2011). The functional organization and capacity limits of working memory. Current Directions in Psychological Science, 20(4), 240-245. doi:10.1177/0963721411415340

Macnamara, B. N., Moore, A. B., \& Conway, A. R. (2011). Phonological similarity effects in simple and complex span tasks. Memory \& Cognition, 39(7), 1174-1186. doi:10.3758/s 13421-011-0100-5

Matsui, M., \& Nakatsubo, T. (2007). Gojugo no kategori niokeru tangoshutudenhindo [Frequency in the recall of words belonging to 55 categories]. The Journal of Liberal Arts and Sciences, University of Toyama, 35, 61-84.

McCabe, D. P. (2008). The role of covert retrieval in working memory span tasks: Evidence from delayed recall tests. Journal of Memory and Language, 58(2), 480-494. doi:10.1016/j.jml.2007.04.004

Meyer, M. L., \& Lieberman, M. D. (2012). Social working memory: Neurocognitive networks and directions for future research. Frontiers in Psychology, 3, 571. doi:10.3389/fpsyg.2012.00571 
Meyer, M. L., Spunt, R. P., Berkman, E. T., Taylor, S. E., \& Lieberman, M. D. (2012). Evidence for social working memory from a parametric functional MRI study. Proceedings of the National Academy of Sciences, 109(6), 1883-1888. doi:10.1073/pnas.1121077109

Miyake, A., \& Saito, S. (2001). Sadokioku no genjo to tembo [Current trends and future directions in working memory research]. Japanese Journal of Psychology, 72, 336-350. [in Japanese with an English Abstract]

Meyer, M. L., Taylor, S. E., \& Lieberman, M. D. (2015). Social working memory and its distinctive link to social cognitive ability: An fMRI study. Social Cognitive and Affective Neuroscience, 10(10), 1338-1347. doi:10.1093/scan/nsv065

Neath, I., VanWormer, L. A., Bireta, T. J., \& Surprenant, A. M. (2014). From Brown-Peterson to continual distractor via operation span: A SIMPLE account of complex span. Canadian Journal of Experimental Psychology, 68(3), 204-211. doi:10.1037/cep0000018

Oberauer, K., Farrell, S., Jarrold, C., \& Lewandowsky, S. (2016). What limits working memory capacity? Psychological Bulletin, 142(7), 758. doi:10.1037/bul0000046

Oberauer, K., Lewandowsky, S., Farrell, S., Jarrold, C., \& Greaves, M. (2012). Modeling working memory: An interference model of complex span. Psychonomic Bulletin \& Review, 19(5), 779-819. doi:10.3758/s13423-012-0272-4

Ogawa, T. (1972). Gojuni kategori ni zokusuru go no shutsugenhindohyo [Normative data for verbal items in 52 categories]. The Journal of the Literary Association of Kwansei Gakuin University, 22(3), 1-68.

Osaka, M. (2002). Wakingu memori: Nou no memocho [Working memory: The sketchpad in the brain]. Tokyo: Shinyosha. 
Polyn, S. M., Norman, K. A., \& Kahana, M. J. (2009a). A context maintenance and retrieval model of organizational processes in free recall. Psychological Review, 116(1), 129-156. doi:10.1037/a0014420

Polyn, S. M., Norman, K. A., \& Kahana, M. J. (2009b). Task context and organization in free recall. Neuropsychologia, 47(11), 2158-2163.

doi:10.1016/j.neuropsychologia.2009.02.013

Portrat, S., Barrouillet, P., \& Camos, V. (2008). Time-related decay or interference-based forgetting in working memory? Journal of Experimental Psychology: Learning, Memory, and Cognition, 34(6), 1561-1564. doi:10.1037/a0013356

Raaijmakers, J. G. W., \& Shiffrin, R. M. (1980). SAM: A theory of probabilistic search of associative memory. In G. Bower (Ed.), The psychology of learning and motivation (Vol. 14, pp. 207-262). New York, NY: Academic Press. doi:10.1016/S0079-7421(08)60162-0

Radvansky, G. A., Spieler, D. H., \& Zacks, R. T. (1993). Mental model organization. Journal of Experimental Psychology: Learning, Memory, and Cognition, 19(1), 95-114. doi:10.1037/0278-7393.19.1.95

Raghubar, K. P., Barnes, M. A., \& Hecht, S. A. (2010). Working memory and mathematics: A review of developmental, individual difference, and cognitive approaches. Learning and Individual Differences, 20(2), 110-122. doi:10.1016/j.lindif.2009.10.005

Rich, S. S., \& Taylor, H. A. (2000). Not all narrative shifts function equally. Memory \& Cognition, 28(7), 1257-1266. doi:10.3758/BF03211825

Saito, S., \& Miyake, A. (2004). On the nature of forgetting and the processing-storage relationship in reading span performance. Journal of Memory and Language, 50(4), 425443. doi:10.1016/j.jml.2003.12.003 
Sakuma, N., Ijuin, M., Fushimi, T., Tatsumi, I., Tanaka, M., Amano, S., \& Kondo, T. (2005). NTT nihongo detabesu shirizu: Nihongo no goitokusei, tangohindo [Japanese NTT database series: Lexical properties of Japanese —Word Imageability]. Tokyo: Sanseido.

Schroeder, P. J., Copeland, D. E., \& Bies-Hernandez, N. J. (2012). The influence of story context on a working memory span task. The Quarterly Journal of Experimental Psychology, 65(3), 488-500. doi:10.1080/17470218.2011.622047

Smith, S. M., \& Vela, E. (2001). Environmental context-dependent memory: A review and metaanalysis. Psychonomic Bulletin \& Review, 8(2), 203-220. doi:10.3758/BF03196157

Speer, N. K., \& Zacks, J. M. (2005). Temporal changes as event boundaries: Processing and memory consequences of narrative time shifts. Journal of Memory and Language, 53(1), 125-140. doi:10.1016/j.jml.2005.02.009

Srull, T. K., \& Wyer, R. S. (1989). Person memory and judgment. Psychological Review, 96(1), 58-83. doi:10.1037/0033-295X.96.1.58

Tanaka, T., Sugimoto, M., Tanida, Y., \& Saito, S. (2014). The influences of working memory representations on long-range regression in text reading: an eye-tracking study. Frontiers in Human Neuroscience, 8, 765. doi:10.3389/fnhum.2014.00765

Taylor, H. A., \& Tversky, B. (1997). Indexing events in memory: Evidence for index dominance. Memory, 5(4), 509-542. doi:10.1080/741941434

Tehan, G., Hendry, L., \& Kocinski, D. (2001). Word length and phonological similarity effects in simple, complex, and delayed serial recall tasks: Implications for working memory. Memory, 9(4-6), 333-348. doi:10.1080/09658210042000049 
Towse, J. N., \& Hitch, G. J. (1995). Is there a relationship between task demand and storage space in tests of working memory capacity? The Quarterly Journal of Experimental Psychology Section A, 48(1), 108-124. doi:10.1080/14640749508401379

Towse, J. N., Cowan, N., Hitch, G. J., \& Horton, N. J. (2008). The recall of information from working memory: Insights from behavioural and chronometric perspectives. Experimental Psychology, 55(6), 371-383. doi:10.1027/1618-3169.55.6.371

Towse, J. N., Hitch, G. J., Horton, N., \& Harvey, K. (2010). Synergies between processing and memory in children's reading span. Developmental Science, 13(5), 779-789. doi:10.1111/j.1467-7687.2009.00929.x

Turner, M. L., \& Engle, R. W. (1989). Is working memory capacity task dependent? Journal of Memory and Language, 28(2), 127-154. doi:10.1016/0749-596X(89)90040-5

Unsworth, N., \& Engle, R. W. (2007a). The nature of individual differences in working memory capacity: Active maintenance in primary memory and controlled search from secondary memory. Psychological Review, 114(1), 104-132. doi:10.1037/0033-295X.114.1.104

Unsworth, N., \& Engle, R. W. (2007b). On the division of short-term and working memory: An examination of simple and complex span and their relation to higher order abilities. Psychological Bulletin, 133(6), 1038-1066. doi:10.1037/0033-2909.133.6.1038

Unsworth, N., Fukuda, K., Awh, E., \& Vogel, E. K. (2014). Working memory and fluid intelligence: Capacity, attention control, and secondary memory retrieval. Cognitive Psychology, 71, 1-26. doi:10.1016/j.cogpsych.2014.01.003

Unsworth, N., \& Spillers, G. J. (2010). Working memory capacity: Attention control, secondary memory, or both? A direct test of the dual-component model. Journal of Memory and Language, 62(4), 392-406. doi:10.1016/j.jm1.2010.02.001 
van Casteren, M., \& Davis, M. H. (2007). Match: A program to assist in matching the conditions of factorial experiments. Behavior Research Methods, 39(4), 973-978. doi:10.3758/BF03192992

Wagenmakers, E. J., Love, J., Marsman, M., Jamil, T., Ly, A., Verhagen, J., ... Morey, R. D. (2018). Bayesian inference for psychology. Part II: Example applications with JASP. Psychonomic Bulletin and Review, 25(1), 58-76. http://doi.org/10.3758/s13423-0171323-7

Wagenmakers, E. J., Wetzels, R., Borsboom, D., \& Van Der Maas, H. L. (2011). Why psychologists must change the way they analyze their data: the case of psi: comment on Bem (2011). Journal of Personality and Social Psychology, 100(3), 426-432. doi: $10.1037 / \mathrm{a} 0022790$

Waters, G. S. (1996). The measurement of verbal working memory capacity and its relation to reading comprehension. Quarterly Journal of Experimental Psychology Section A, 49, 51-79. doi:10.1080/713755607

Watkins, O. C., \& Watkins, M. J. (1975). Buildup of proactive inhibition as a cue-overload effect. Journal of Experimental Psychology: Human Learning and Memory, 104(4), 442-452. doi:10.1037/0278-7393.1.4.442

Zacks, J. M., Speer, N. K., \& Reynolds, J. R. (2009). Segmentation in reading and film comprehension. Journal of Experimental Psychology: General, 138(2), 307-327. doi:10.1037/a0015305

Zwaan, R. A. (1999). Five dimensions of narrative comprehension: The event-indexing model. In S. R. Goldman, A. C. Graesser, \& P. van den Broek (Eds.), Narrative comprehension, 
causality, and coherence: Essays in honor of Tom Trabasso (pp. 93-110). Mahwah, NJ: Lawrence Erlbaum Associates.

Zwaan, R. A., \& Radvansky, G. A. (1998). Situation models in language comprehension and memory. Psychological Bulletin, 123(2), 162-185. doi:10.1037/0033-2909.123.2.162

Zwaan, R. A., Langston, M. C., \& Graesser, A. C. (1995). The construction of situation models in narrative comprehension: An event-indexing model. Psychological Science, 6(5), 292297. doi:10.1111/j.1467-9280.1995.tb00513.x 


\section{Footnotes}

${ }^{1}$ For the first four participants, on the completion of the recalling of items in a trial, they said, "I am finished". Immediately, the experimenter started the next trial. As in the main text, this procedure was changed for the rest of the 28 participants. The change of procedure was introduced for the comfort of the participants. This change, however, did not alter the pattern of results of the statistical tests for both scoring methods, irrespective of whether the data from the first four participants were included or excluded. Therefore, the analysis included data from all 32 participants. Due to a computer trouble, one sentence was shown longer, beyond the point at which the experimenter pressed a key to show the next sentence. It occurred in a 2 -sentence trial, in which most of the participants responded correctly and it hardly affected the results. Removing the data of the participant, in fact, did not alter the statistical pattern; therefore, the data were included in the analysis.

${ }^{2}$ Although we conducted one-tailed analyses throughout Experiments 1-4, two-sided analysis should be included to investigate the null effect of Experiment 4 for the sake of completeness. Thus, the Bayes factor was calculated based on the following two hypotheses: 1) the null hypothesis that the mean scores of two conditions are the same, and 2) the alternative hypothesis that the mean score of the single object condition differs from that of the constant object condition. With these hypotheses, $\mathrm{BF}_{01}$ was 5.47 , which was considered as substantial evidence supporting the null effect (Jeffreys, 1961). 
Table 1

Data of RSTs in Experiments 1 - 4

\begin{tabular}{|c|c|c|c|c|c|c|}
\hline & \multicolumn{3}{|c|}{ Descriptive statistics } & \multicolumn{3}{|c|}{ Correlations } \\
\hline & $M$ & $S D$ & Range & 1 & 2 & 3 \\
\hline \multicolumn{7}{|l|}{ Experiment 1} \\
\hline 1. Standard RST & 22.5 & 5.37 & $12-35$ & - & & \\
\hline 2. Single person & 28.6 & 4.51 & 19-37 & $.69[.46, .84]$ & - & \\
\hline 3. Multiple person & 25.8 & 6.77 & $11-37$ & $.54[.24, .75]$ & $.44[.11, .69]$ & - \\
\hline \multicolumn{7}{|l|}{ Experiment 2} \\
\hline 1. Standard RST & 30.1 & 4.89 & $21-39$ & - & & \\
\hline 2. Single person & 32.2 & 5.64 & $19-42$ & $.68[.44, .83]$ & - & \\
\hline 3. Multiple person & 30.3 & 6.25 & $18-39$ & $.61[.33, .79]$ & $.67[.41, .82]$ & - \\
\hline \multicolumn{7}{|l|}{ Experiment 3} \\
\hline 1. Standard RST & 29.9 & 5.14 & $17-39$ & - & & \\
\hline 2. Single person & 31.6 & 5.99 & $16-42$ & $.73[.55, .84]$ & - & \\
\hline 3. Constant person & 30.5 & 5.35 & $17-42$ & $.64[.43, .78]$ & $.79[.65, .88]$ & - \\
\hline \multicolumn{7}{|l|}{ Experiment 4} \\
\hline 1. Standard RST & 30.3 & 5.89 & $17-40$ & - & & \\
\hline 2. Single object & 30.9 & 6.13 & $16-42$ & $.67[.51, .78]$ & - & \\
\hline 3. Constant object & 31.4 & 6.44 & $14-42$ & $.65[.49, .77]$ & $.78[.67, .86]$ & - \\
\hline
\end{tabular}

Note. $95 \%$ confidence intervals in square brackets 
Figure 1. Schematic illustration of the three conditions in the experiments

\section{Multiple person}

Trial 1

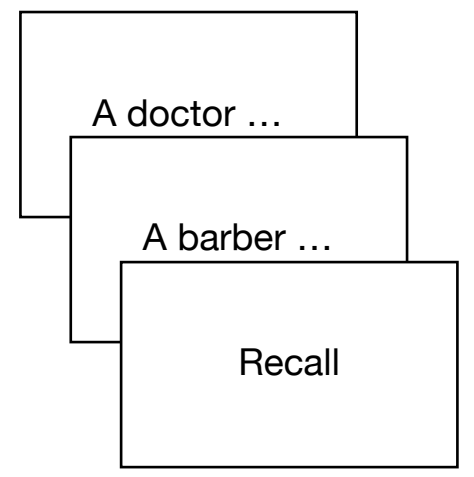

Trial 2

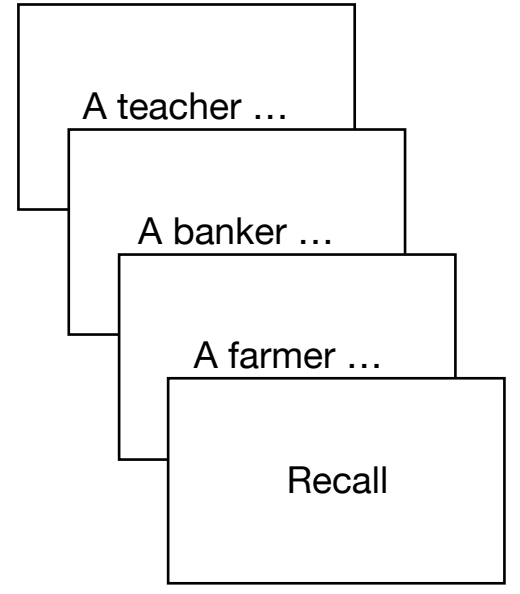

Trials continued
Single person

Trial 1

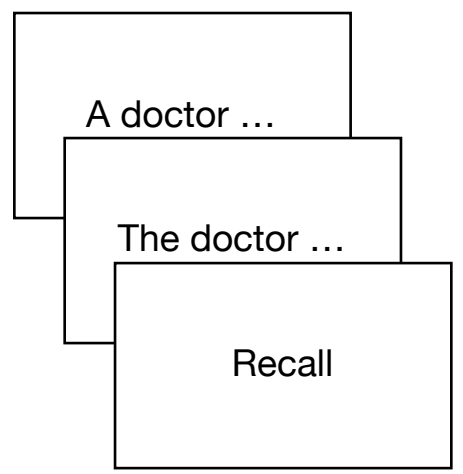

Trial 2

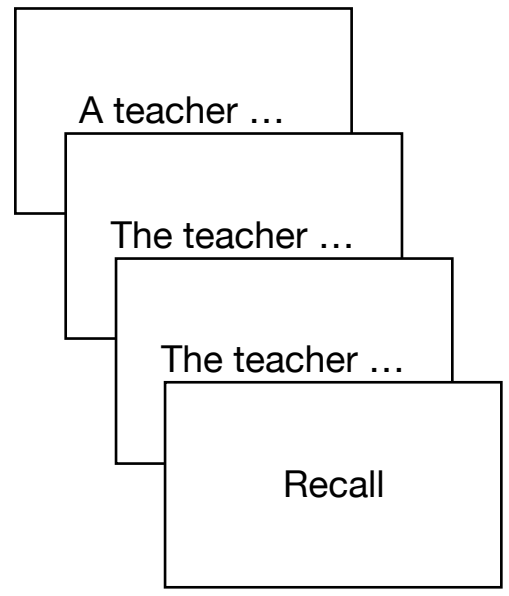

Trials continued

\section{Constant person}

Trial 1

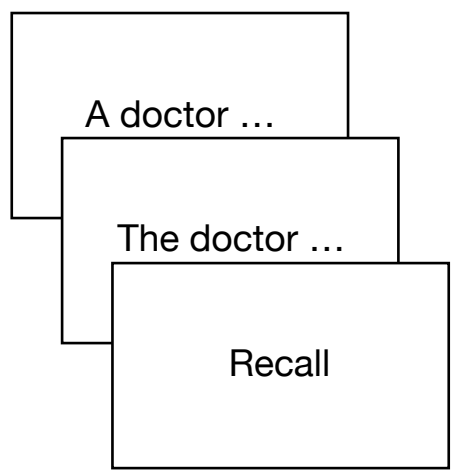

Trial 2

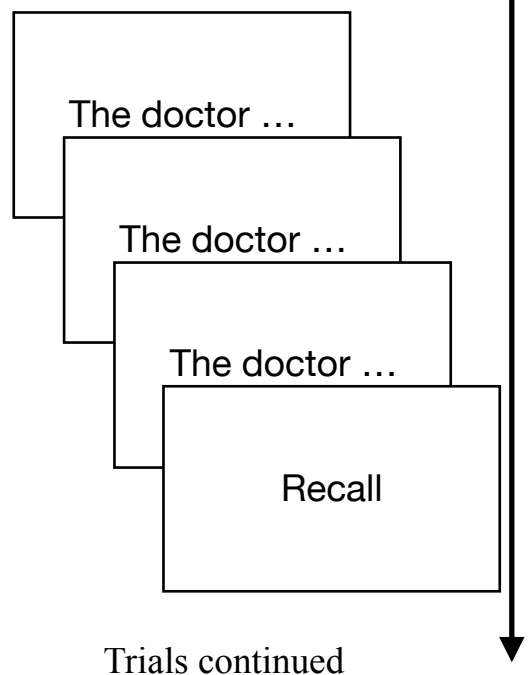

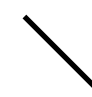

Conditions used in Experiment 1 and 2

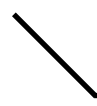

Conditions used in Experiment 3 
Figure 2. Schematic illustration of the temporal progress in a trial in Experiment 1

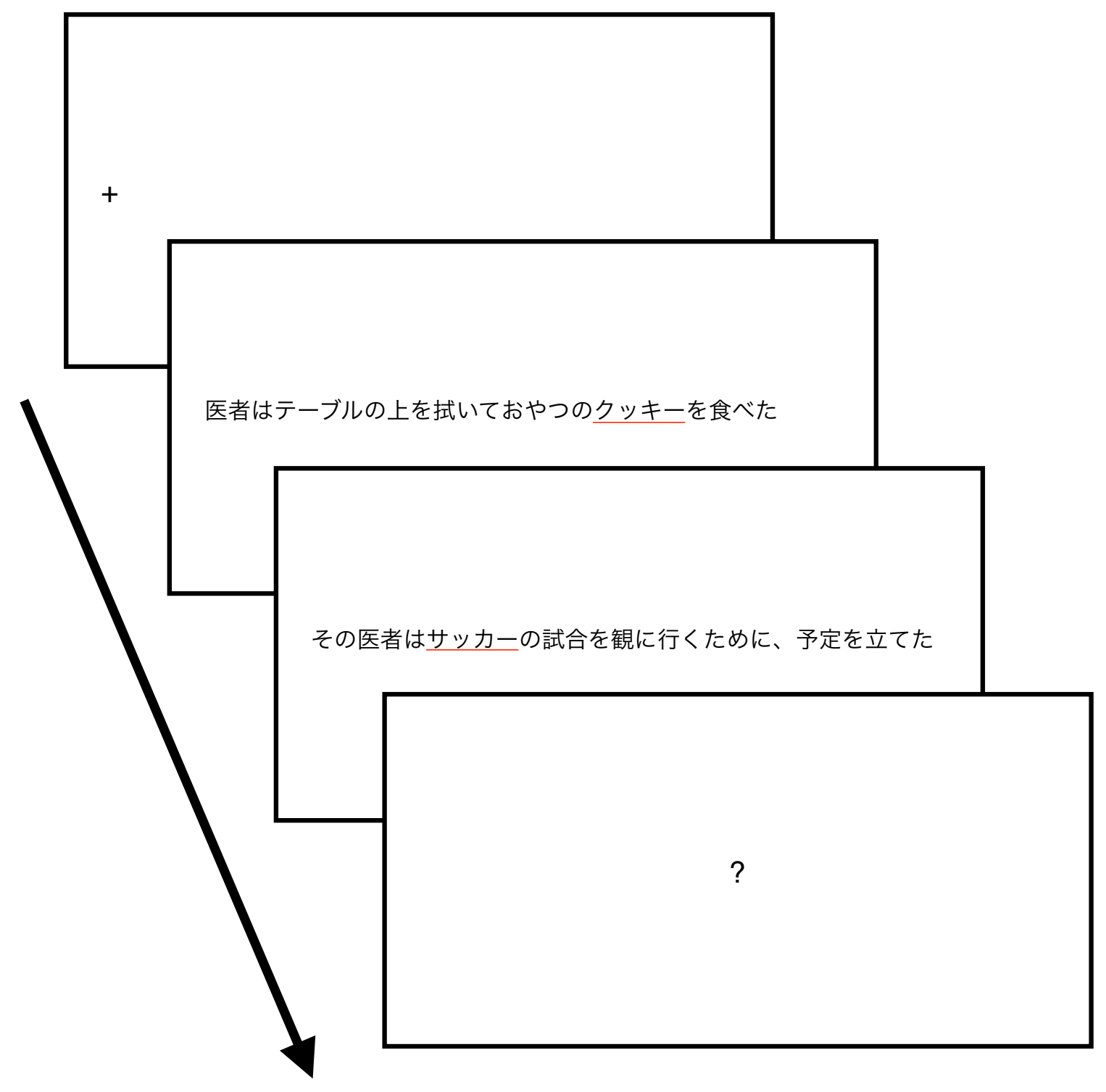


Figure 3. Schematic illustration of the temporal progress in a trial in Experiment 2

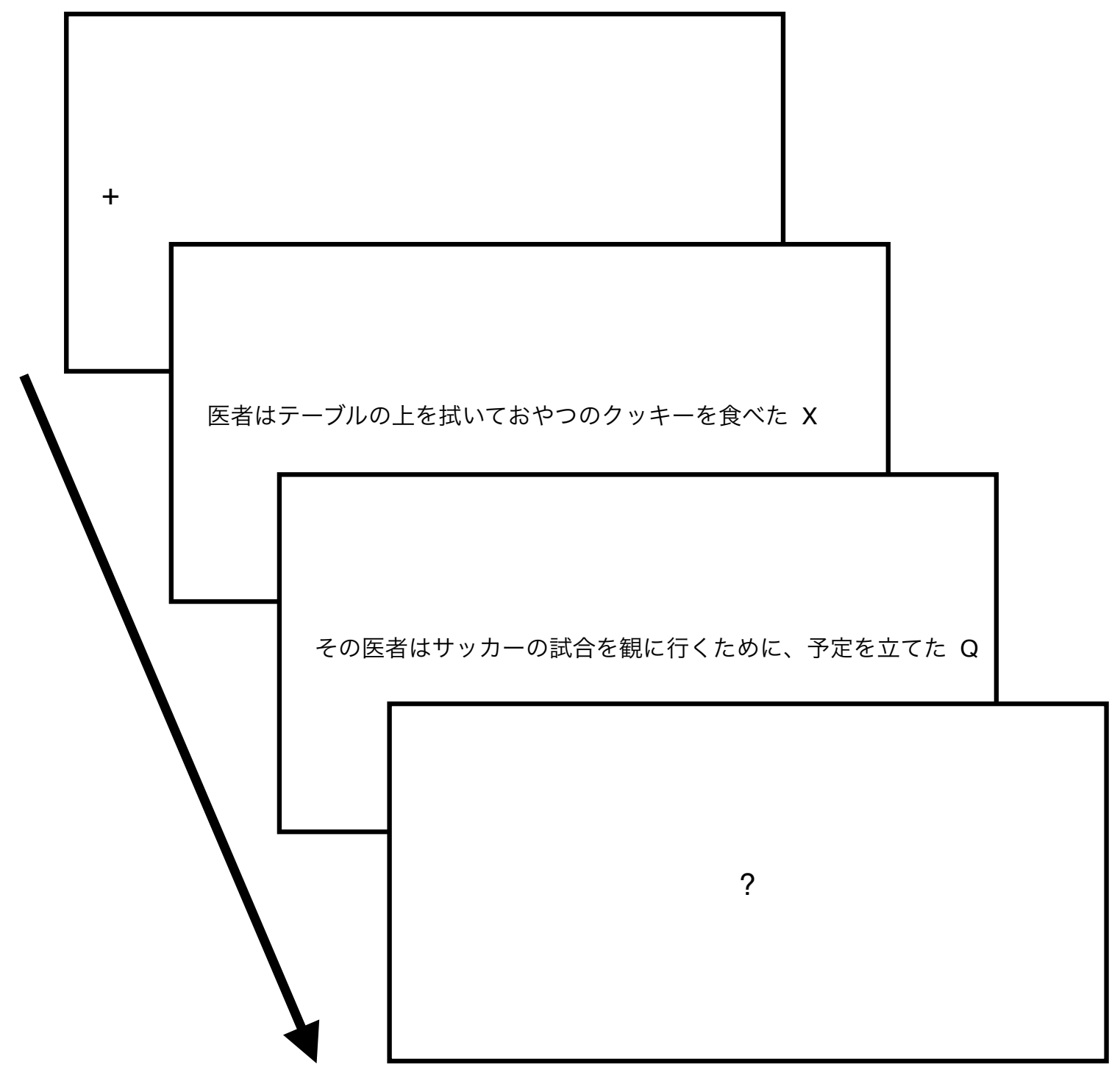




\section{Appendix}

\section{Reading Time}

Experiment 1. The mean reading time for a sentence was calculated for the participants. The reading time for a sentence when a computer-related error occurred was excluded. The mean reading time was longer in the single person condition $(M=5.18$ seconds $)$ than in the multiple person condition $(\mathrm{M}=5.06$ seconds $), t(31)=2.76, p<.01$.

Experiment 2. The mean reading time was longer in the single person condition $(\mathrm{M}=5.90$ seconds) than in the multiple person condition was ( $\mathrm{M}=5.74$ seconds $), t(31)=4.41, p<.001$.

Experiment 3. The second and later sentences in each trial in the single person condition and all the sentences except the first sentence in the first trial in the constant person condition included a demonstrative, "sono" ("the"). Therefore, comparing the reading times of the second and later sentences for both conditions enabled controlling for the sentence length. A two-way repeated measures ANOVA with sentence position factor (the first position and rest positions conditions) and person representation factor (single person and constant person conditions) was performed. The first position condition focused on the reading time for the first sentences in the trials. The rest positions condition targeted the second and later sentences in the trials. The person representation factor did not lead to statistical differences, $F(1,46)=1.83, p=0.18$. The sentence position factor affected the reading time, $F(1,46)=150.8, p<.001$. The interaction between the two factors was statistically significant, $F(1,46)=10.2, p<.01$. For the observed interaction, the simple main effect was tested. For the first position, the reading times differed in the two conditions of the person representation factor $(M=5.19$ and 5.30 seconds for the single person condition and the constant person condition, respectively), $t(1,46)=2.78, p<.01$. For the rest positions condition, in contrast, the reading times did not statistically differ $(M=5.72$ and 
PERSON-BASED ORGANISATION IN WM

5.70 seconds for single person condition and constant person condition, respectively), $t(1,46)=$ $0.56, p=.58$.

Experiment 4. An analysis, as done in Experiment 3, was performed to Experiment 4. The object representation factor (the single object vs. the constant object conditions) did not show statistical differences, $F(1,71)=2.85, p=0.10$. The sentence position factor affected the reading time, $F(1,71)=87.7, p<.001$. The interaction between the two factors was statistically significant, $F(1,71)=21.9, p<.001$. Because the interaction was observed, the analysis of the simple main effect on both of the first and rest position conditions was performed. For the first position, the reading times differed in the two conditions of the object representation factor $(\mathrm{M}=$ 5.22 and 5.36 seconds for the single object condition and the constant object condition, respectively), $t(71)=3.34, p<.01$. For the rest position, however, the reading times did not differ in the two conditions $(M=5.66$ and 5.64 seconds for the single object condition and the constant object condition, respectively), $t(71)=0.89, p=0.37$.

\section{Discussion}

In Experiments 1 and 2, the reading time was longer in the single person condition compared to that in the multiple person condition. This could be due to the differences in the length of the sentences, which included "sono" ("the") only in the single person condition.

In Experiment 3 and 4, the analysis of reading time also suggested that long sentences, which included a demonstrative word, required a longer duration for reading (first position condition). When the lengths of the sentences were matched, the reading time did not statistically differ by the presentation of person representation or object representation (rest positions condition). As the duration for the first sentences was likely to have little influence on memory 
and the duration for the rest sentences was likely to be equivalent in the two conditions, the differences in WM performance in Experiment 3 can hardly be attributed to the differences in the duration of reading. 